\title{
Effects of trial duration on overall and momentary rates of maintained autoshaped keypecking: Choice and single-stimulus trials
}

\author{
NANCY S. HEMMES and BRUCE L. BROWN \\ Queens College, City University of New York, Flushing, New York \\ and Graduate School and University Center, City University of New York, New York, New York \\ and \\ SOLEDAD CABEZA DE VACA \\ Graduate School and University Center, City University of New York, New York, New York
}

\begin{abstract}
Pigeons were exposed to differentially cued autoshaping trials in which conditioned stimuli were followed by food after 6 or $14 \mathrm{sec}$. Average and momentary rates of keypecking were examined on two types of unreinforced test trials: single-stimulus probe trials and simultaneous choice trials, each $40 \mathrm{sec}$ in duration. Rates averaged over the 40-sec test trials did not favor the cue associated with the shorter delay to food (the short-delay cue) on either type of test trial; however, average rates prior to the scheduled time of food delivery were reliably higher for the short-delay cue on choice trials. Momentary rates of keypecking during choice trials varied as a function of both cue and elapsed time from trial onset. At short elapsed trial times, rate of pecking was higher for the short-delay cue, with this difference reversing at longer times. A reversal of the programmed relation between key color and delay to food presentation for 5 birds confirmed the generality of these findings. Implications of these data for models of Pavlovian conditioning and for methods of assessing conditioned response strength are discussed.
\end{abstract}

As with other Pavlovian preparations, speed of acquisition under autoshaping procedures shows strong dependence upon parameters of reinforcement (Balsam, 1984; Gibbon, Baldock, Locurto, Gold, \& Terrace, 1977; Gibbon, Farrell, Locurto, Duncan, \& Terrace, 1980; Jenkins, Barnes, \& Barerra, 1981). However, a more traditional measure of strength of keypeck responding-rate of maintained responding-shows less sensitivity to these variables (Balsam \& Payne, 1979; Crawford, Steirn, \& Pavlik, 1985; Gonzalez, 1974; Kay, Hemmes, \& Brown, 1984; Lucas, Deich, \& Wasserman, 1981; Newlin \& LoLordo, 1976; O'Connell \& Rashotte, 1982; Perkins et al., 1975).

These findings challenge the comparability of autoshaped keypecking with other indexes of Pavlovian conditioning. Gibbon et al. (1980) addressed this issue, noting that measures of keypecking pertaining to the first peck of a trial generally behave similarly to more traditional preparations, whereas measures that include all of the pecks in a trial may not. In their study of autoshaped responding, strength of the first response (latency) in a trial increased with increasing probability of reinforce-

This research was supported in part by Grant MH 39950-01 from the National Institute of Mental Health, and by PSC/CUNY Grant 6-64350. We gratefully acknowledge the assistance of David Kay in the development of this project. Requests for reprints may be sent to Nancy Hemmes, Department of Psychology, Queens College-CUNY, Flushing, NY 11367. ment, while strength of subsequent responses (rate) varied inversely with reinforcement probability. Similar effects were reported by Picker and Poling (1982), who used a within-subjects design. Overall rates of responding on single-stimulus trials favored the partially reinforced cue; however, the locus of the first peck on choice trials revealed a clear preference for a cue associated with a $100 \%$ probability of reinforcement. This effect has also appeared in manipulations of reinforcer magnitude. O'Connell and Rashotte (1982, Experiment 1) found no effect of reinforcer magnitude on overall rates of responding; however, analysis of momentary rates revealed a direct relation between reinforcer magnitude and response rate early in the trial, but not late.

In summary, several studies sugggest that the inadequacy of overall response rate as an index of response strength in autoshaping is attributable to changes in rate of responding during the trial stimulus. In the present study, we examined how both overall and momentary responding change as a function of another important parameter in Pavlovian conditioning-delay to reinforcement from trial (conditioned stimulus, or CS) onset. In a within-subjects design, pigeons were exposed to differentially cued autoshaping trials in which one CS (the short-delay cue) was paired with food after $6 \mathrm{sec}$, and another CS (the long-delay cue) was paired with food after $14 \mathrm{sec}$. In order to maximize the opportunity for observing differences in response strength controlled by the two cues, unreinforced choice trials (cf. O'Connell \& 
Rashotte, 1982; Picker, Grossett, Thomas, \& Poling, 1984; Picker \& Poling, 1982) were employed in which both CSs were presented simultaneously for $40 \mathrm{sec}$. For comparison, unreinforced single-stimulus probe trials of 40 -sec duration were also presented.

Data from a variety of preparations indicate that greater strength of responding should be controlled by the shortdelay cue (cf. Black \& Prokasy, 1972; Pavlov, 1927; Poling, Thomas, Hall-Johnson, \& Picker, 1985). In accordance with contemporary theoretical views, this difference in response strength would reflect differential associative strength or value acquired by the cues (Gibbon \& Balsam, 1981; Rescorla \& Wagner, 1972). However, a molar assessment of value may not adequately describe the nature of the acquired associative relations. In addition to control by overall value acquired by each cue, pecking might also be expected to show systematic within-CS changes (temporal conditioning) as a function of delay to reinforcement (e.g., see Ellison, 1964; Gibbon et al., 1977; Millenson, Kehoe, \& Gormezano, 1977; Pavlov, 1927). In interpreting within-CS temporal patterning, Pavlov argued that the effective CS is actually a stimulus compound composed of an exteroceptive cue (the nominal CS) plus its momentary duration. Although overall associative value acquired by the constant exteroceptive element may be invariant within a trial, values accruing to the temporal element would vary with elapsed time. Thus, in the present study, the short- and long-delay cues may be expected to generate differential response strengths owing to differences in overall value and to variations in momentary values within a trial. Performance would therefore reflect both of these sources of control over keypecking.

\section{METHOD}

\section{Subjects}

Two squads of naive, adult male White Carneaux pigeons were food-deprived, but had continuous access to water. The subjects in Squad 1 (Nos. 1400, 849, 1315, 5488, and 5369) were maintained at $80 \%$ of ad-lib weight, and Squad 2 subjects (Nos. 1041, 4847,3542 , and 4261 ) were maintained at $75 \%$. Three other pigeons were discarded because they failed to meet an acquisition criterion of a minimum of 1 response per minute in 30 sessions. Experimental observations were conducted during the first 6 light hours of a 14:10-h light:dark cycle.

\footnotetext{
Apparatus

A standard pigeon chamber (BRS/LVE, No. 132-02) containing a three-key intelligence panel (BRS/LVE, No. 141-10) was employed. The clear Lucite center and left keys could be illuminated with a white, red, or green light. The right key remained dark and inoperable throughout the experiment. Food-tray presentations were timed from the bird's interruption of a photobeam directed across the hopper cavity. A second chamber, reserved for magazine training, was similar to the first, except for its stainless steel reflective walls and ceiling. Masking noise was provided by a chamber fan and white noise.

The experiment was controlled by electromechanical equipment located in an adjoining room. On all trials, keypeck responses were recorded on counters in successive 2 -sec intervals, and, during test trials, on a four-pen Rustrak event recorder.
}

\section{Procedure}

Following magazine training, the birds in Squad 1 were exposed to experimental sessions conducted 5 days a week. This phase of the experiment lasted for 48 sessions (the subjects were exposed to an additional 2-15 sessions prior to the reversal described below). The sessions comprised three types of trials: autoshaping (training) trials, probe tests, and choice tests. Both keys were illuminated continuously throughout a session, except during reinforcement and immediately prior to a trial, when the keys were darkened momentarily for less than $0.5 \mathrm{sec}$. Keylights were white except during trials that were signaled by a change in color of one or both keys to a red or a green light (the CSs). The intertrial interval, defined by the absence of CS or unconditioned stimulus (US) cues, was $60 \mathrm{sec}$ in duration.

On autoshaping trials, a CS was presented on a single key for a total of $20 \mathrm{sec}$, and response-independent reinforcement was presented after a given delay from trial onset. On short-delay (SD) trials, the CS was green and delay to reinforcement was $6 \mathrm{sec}$; on long-delay (LD) trials, the CS was red and delay to food was $14 \mathrm{sec}$. Reinforcement consisted of a 2 -sec access to mixed grain, timed from the insertion of the bird's head into the hopper aperture. During reinforcer presentation, the CS timer was stopped.

On probe- and choice-test trials, CS duration was $40 \mathrm{sec}$ and reinforcement was omitted. During probe tests, a red or green CS was presented on a single key. On choice tests, both red and green CSs were presented simultaneously on separate keys.

Sessions consisted of 32 autoshaping, four probe, and four choice trials, presented in one of 16 different random orders that were block-randomized across sessions. A constraint was that two test trials could not occur successively. For each trial type, cue and position were ordered randomly in four-trial blocks, with the constraint that each CS appeared equally often on the center and left keys.

For each block of four consecutive sessions, keypecking was recorded on choice trials for two sessions, on probe trials for one session, and on autoshaping trials for another session. The order of these sessions was randomized within each block.

The procedure for Squad 2 was identical to that for Squad 1, except that (1) autoshaping trials were truncated in duration-that is, terminated upon reinforcer delivery, and (2) after 48 sessions, Squad 2 birds were exposed to four extended choice sessions alternating among additional training sessions. On extended choice sessions, the SD and LD CSs were presented simultaneously and continuously for $\mathbf{4 0}$ min while no other events were programmed. Cue and position were balanced across sessions and birds.

After experimentation with Squad 2 birds was completed, the birds in Squad 1 were exposed to a color reversal on autoshaping trials for 48 additional sessions. SD trials $(6 \mathrm{sec})$ were now signaled by the red cue and LD trials were signaled by the green cue. The procedure was otherwise identical to the prereversal conditions for these birds, except that no data were recorded for autoshaping trials. Therefore, in each four-session block, keypeck responses were recorded on choice trials for two sessions and on probe trials for two sessions, with session order randomly determined.

\section{RESULTS}

Visual inspection of keypeck rate patterns across sessions indicated stability of test-trial behavior by Session 24; thus, analyses were based upon overall performance during Sessions 25-48 during the prereversal phase. For the reversal phase, analyses were based upon overall performance during Sessions 17-48.

Preliminary analyses indicated no reliable main effects of procedures applied to the two squads of birds and no 
interactions of procedure with any treatment variables. Therefore, prereversal data were analyzed for a single group of 9 subjects. Comparisons between prereversal and reversal data were based upon the 5 birds (Squad 1) exposed to both phases.

\section{Probability and Latency of Response}

The effect of delay of reinforcement was assessed by comparing performance for SD and LD cues during both probe- and choice-test trials. The first question was whether the birds would exhibit stronger behavioral control by the SD than by the LD cue in terms of higher probability of responding and shorter latencies. Data for these measures were available during the prereversal phase only. Since there were twice as many opportunities to respond to a cue on choice than on probe trials, probabilities were based on different numbers of trials for the two trial types. Group mean probabilities of at least one peck on a test trial for SD and LD cues were, respectively, .88 and .88 during probe trials, and .82 and .66 during choice trials. Probability did not differ reliably between delay-to-reinforcement cues for either trial type ( $F$ tests, $\alpha=.05$ ).

An alternative measure on choice trials is the probability that the first peck of a trial was directed to one delay cue (Picker \& Poling, 1982). On this measure, all 9 birds exhibited a preference for the SD over the LD key (group means: $85 \%$ and $15 \%$, respectively).

For each bird, median peck latency was determined for each delay cue on each trial type, counting pecks to both keys on choice trials. Group mean median latencies to peck were shorter for pecks to the SD than to the LD key on both probe ( 1.02 vs. $2.95 \mathrm{sec})$ and choice ( 0.89 vs. $14.72 \mathrm{sec})$ tests, with the choice-test difference exceeding that for the probe test. An analysis of variance (ANOVA) yielded a reliable test type $\times$ delay interaction $[F(1,8)=233.22, p<.001]$. A comparison among individual means indicated a significant delay effect on both test types $(t$ tests, $p s<.01)$. Severe heterogeneity of variance of median latencies was eliminated by a $\log ($ median +1$)$ transformation. When the preceding latency analyses were performed on transformed scores, the conclusions were unchanged.

In sum, the effect of delay of reinforcement upon latency was more substantial on choice than on probe trials, and the first-peck measure showed a preference for the SD over the LD key on choice trials. There was no reliable effect of delay upon the overall probability of a keypeck to SD and LD keys.

\section{Response Rate}

The effect of delay to reinforcement upon response rate was evaluated first by comparing average rates between delay cues. Table 1 presents means from individual subjects in both phases for (1) overall keypeck rate during the 40-sec test trials and (2) pre-US keypeck rate (i.e., mean rate during the first $6 \mathrm{sec}$ of the test trial for the SD key and during the first $14 \mathrm{sec}$ for the LD key). Group mean overall rates were not higher for the SD than for the LD cue on either type of test trial during either phase. Indeed, during probe trials, overall rate was reliably higher on the LD key $[F(1,8)=7.38, p<.05]$ for the 9 birds in the prereversal phase, but not in the reversal phase. Choice trials yielded no reliable difference in either

Table 1

Responses per Minute During Short-Delay (SD) and Long-Delay (LD) Cues in Probe- and Choice-Test Trials

\begin{tabular}{|c|c|c|c|c|c|c|c|c|c|}
\hline \multirow[b]{3}{*}{ Bird } & \multirow[b]{3}{*}{ Trial Type } & \multicolumn{4}{|c|}{ Prereversal } & \multicolumn{4}{|c|}{ Reversal } \\
\hline & & \multicolumn{2}{|c|}{$\begin{array}{c}\text { Rate } \\
(40 \mathrm{sec})\end{array}$} & \multicolumn{2}{|c|}{$\begin{array}{c}\text { Rate } \\
\text { (pre-US) }\end{array}$} & \multicolumn{2}{|c|}{$\begin{array}{c}\text { Rate } \\
(40 \mathrm{sec})\end{array}$} & \multicolumn{2}{|c|}{$\begin{array}{c}\text { Rate } \\
\text { (pre-US) }\end{array}$} \\
\hline & & SD & LD & SD & LD & SD & LD & SD & LD \\
\hline \multirow[t]{2}{*}{1400} & Probe & 6.3 & 30.2 & 35.0 & 33.6 & 21.9 & .5 & 69.1 & 1.2 \\
\hline & Choice & 4.9 & 12.0 & 29.4 & 4.8 & 10.6 & 1.0 & 54.5 & .1 \\
\hline \multirow[t]{2}{*}{849} & Probe & 18.4 & 16.5 & 42.5 & 21.8 & 9.6 & 9.5 & 32.8 & 14.5 \\
\hline & Choice & 16.7 & 2.9 & 52.9 & 1.4 & 9.3 & 7.2 & 28.3 & 11.0 \\
\hline \multirow[t]{2}{*}{1315} & Probe & 11.9 & 42.0 & 46.7 & 55.0 & 12.8 & 27.8 & 50.6 & 37.0 \\
\hline & Choice & 7.4 & 18.8 & 41.5 & 12.6 & 5.8 & 3.6 & 35.8 & 3.9 \\
\hline \multirow[t]{2}{*}{5488} & Probe & 25.3 & 39.8 & 73.3 & 51.4 & 22.3 & 66.4 & 68.7 & 70.9 \\
\hline & Choice & 12.8 & 18.5 & 43.8 & 7.2 & 20.0 & 6.3 & 74.4 & 1.3 \\
\hline \multirow[t]{2}{*}{5369} & Probe & 8.9 & 5.8 & 18.3 & 7.9 & 26.8 & 6.5 & 90.9 & 8.1 \\
\hline & Choice & 2.5 & 3.0 & 15.4 & 1.3 & 22.2 & .7 & 101.4 & 1.1 \\
\hline \multirow[t]{2}{*}{1041} & Probe & 5.8 & 11.8 & 25.0 & 22.1 & & & & \\
\hline & Choice & 6.7 & 3.2 & 33.8 & 2.1 & & & & \\
\hline \multirow[t]{2}{*}{4847} & Probe & 46.9 & 100.1 & 158.3 & 138.2 & & & & \\
\hline & Choice & 33.2 & 37.3 & 117.9 & 14.8 & & & & \\
\hline \multirow[t]{2}{*}{3542} & Probe & 6.6 & 25.9 & 28.3 & 36.8 & & & & \\
\hline & Choice & 6.4 & 16.6 & 34.4 & 4.2 & & & & \\
\hline \multirow[t]{2}{*}{4261} & Probe & 1.4 & 5.7 & 4.0 & 3.0 & & & & \\
\hline & Choice & 1.9 & 2.9 & 9.6 & .8 & & & & \\
\hline \multirow[t]{2}{*}{ Mean } & Probe & 14.5 & 30.9 & 47.9 & 41.1 & 18.7 & 22.2 & 62.4 & 26.3 \\
\hline & Choice & 10.3 & 12.8 & 42.1 & 5.5 & 13.6 & 3.8 & 58.9 & 3.5 \\
\hline
\end{tabular}




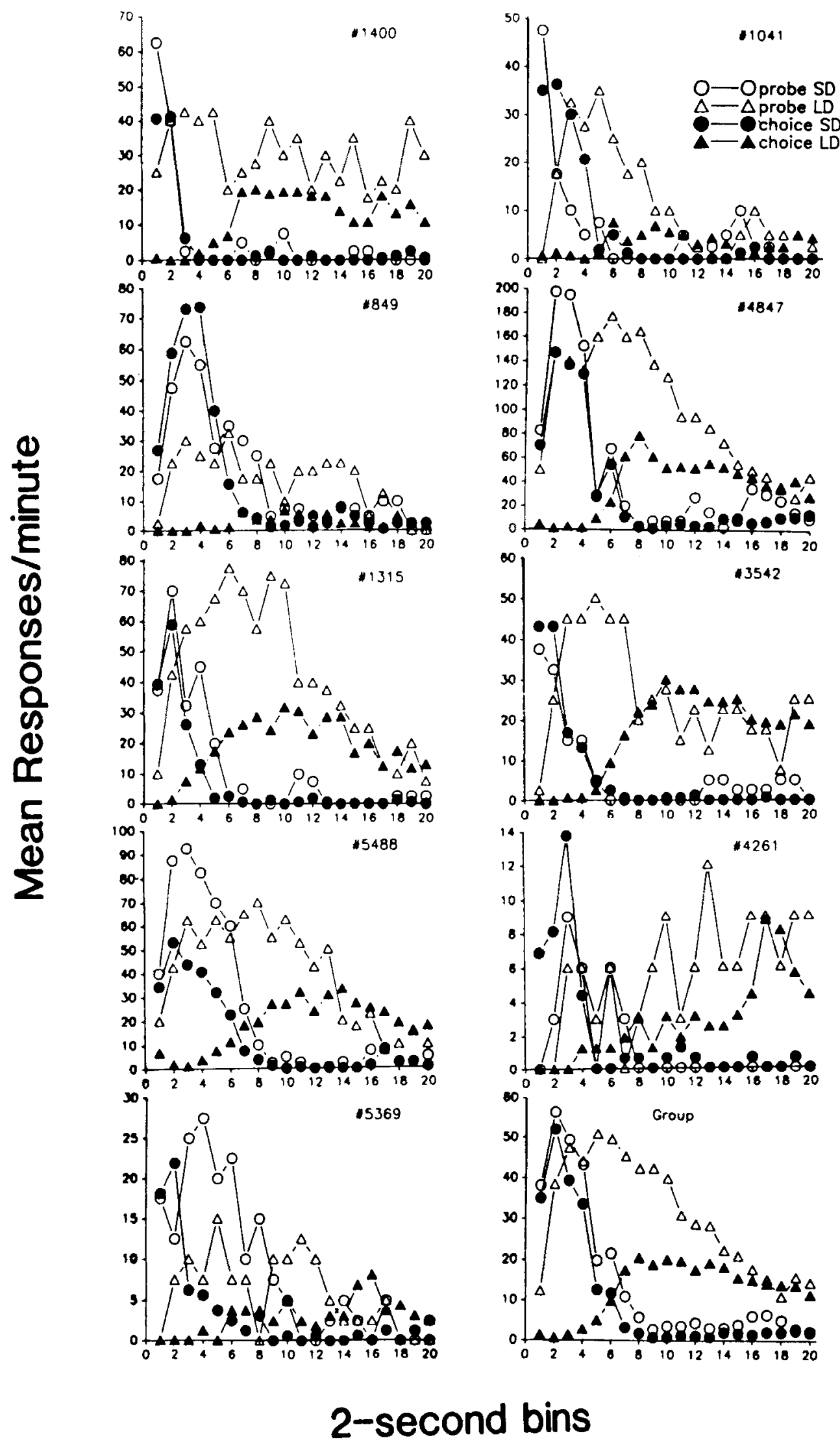

Figure 1. Individual and group response rates for each cue on choice- and probe-test trials. Short- and long-delay cues are indicated as SD and LD, respectively. Note that the ordinate scale differs across birds. 
phase. When the analyses were confined to the data for the birds exposed to both phases (Squad 1), no reliable delay effects were found.

A different pattern was observed when rates during the pre-US interval were compared: group mean rate was reliably higher on the SD than on the LD key during choice trials in both the prereversal $[F(1,8)=11.84$, $p<.01]$ and the reversal $[F(1,4)=14.6, p<.02]$ phases. Probe-trial rates did not yield reliable delay effects in either phase. In sum, during choice trials, but not probe trials, a gross rate measure (pre-US rate) indicated greater response strength associated with the shorter delay. This conclusion was unchanged when analyses were restricted to the data of Squad 1 birds.

The foregoing conventional analyses of behavior are predicated on the assumption that value accrues only to nontemporal properties of CSs. In the following analyses, response rate was examined as a function of (1) delay cues and (2) elapsed time from test-trial onset.

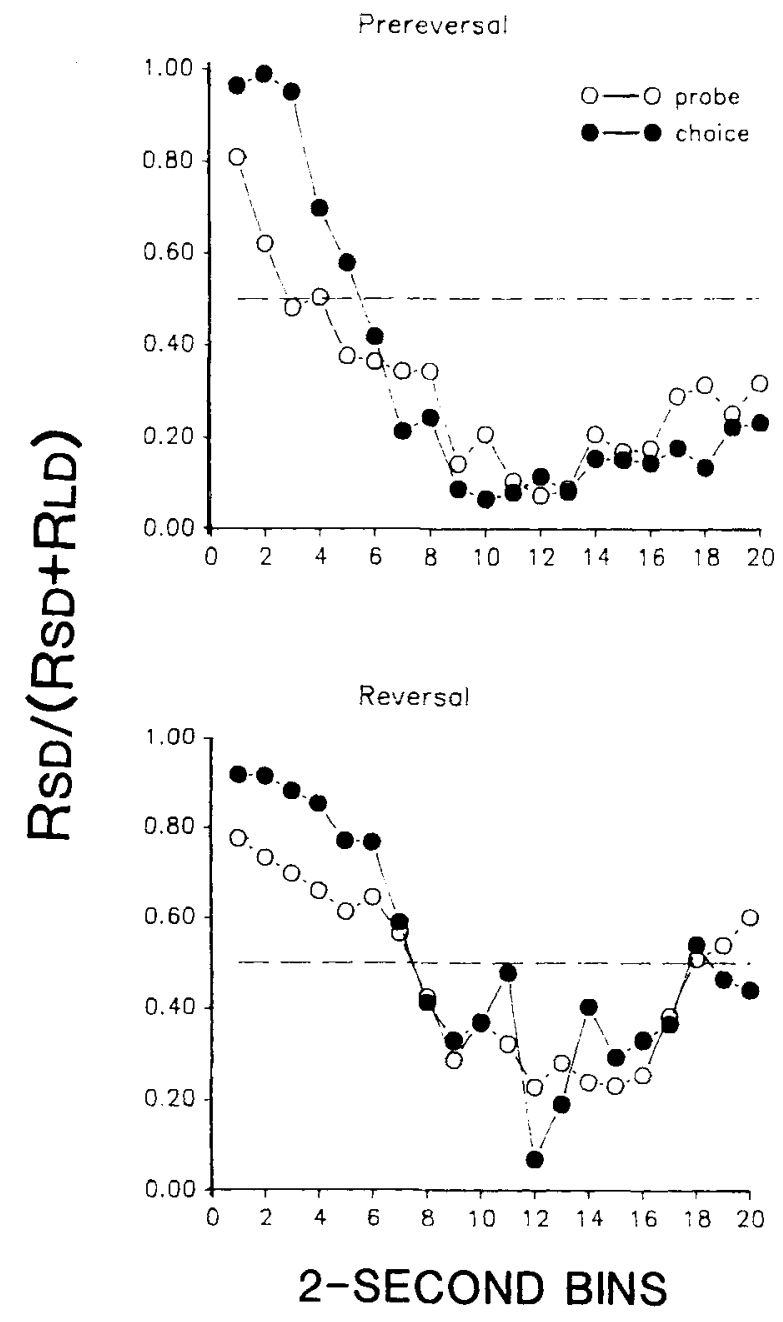

Figure 2. Discrimination ratios [momentary rate of responding during the short-delay (SD) cue divided by the sum of momentary rates during the SD and long-delay (LD) cues] for probe and choice trials. The upper and lower panels depict prereversal and reversal performance, respectively, for the birds in Squad 1.
Figure 1 depicts the time course, in 2-sec time bins, of response rate on each cue separately for each trial type during the prereversal phase. Different ordinate scales were used to accommodate the considerable variability in rate among the 9 birds. However, similar patterns of performance were exhibited by all subjects. Early in test trials of both types, momentary response rates were higher for the SD than for the LD cue, but as time elapsed that difference reversed.

Figure 2 depicts performance of the birds in Squad 1 during both the prereversal (upper panel) and the reversal (lower panel) phases. The time course of performance is represented as a discrimination ratio defined as the momentary rate of response for the SD cue divided by the sum of momentary rates for the SD and LD cues. In those instances in which momentary rates in a bin were both zero ( 9 of 400 cases), a ratio value of .5 was used. During both phases and for each test type, relative response rate was initially higher for the SD than for the LD cue, but as time since trial onset elapsed, the discrimination appeared to reverse with ratio values falling below .5. A phase $\times$ test type $\times$ bin ANOVA revealed a significant bin effect $[F(19,76)=22.04, p<.001]$ and a significant test type $\times$ bin interaction $[F(19,76)=2.24$, $p<.01]$. No effects involving phase were reliable. The interaction reflected the fact that relative rate of responding on the SD key was higher during choice trials than during probe trials early, but not later, in the trial. Of greater interest was the discrimination reversal. The bin effect was reliable for all four functions ( $F$ tests, $p<.001$ ); however, the discrimination crossover was consistent only for choice trials. For each function, $t$ tests ( $d f=4, \alpha=.05$ ) were performed to locate the two time bins containing ratios reliably different from .5 and bracketing the discrimination crossover. For choice trials, the bracketing values were located at Bins 3 and 7 in the prereversal phase, and at Bins 4 and 12 in the reversal phase. For probe trials, during the prereversal phase, the bracketing bins were 2 and 9; during the reversal phase, a reliable difference in Bin 2 was not followed by a significant crossover.

In summary, performance patterns during both phases indicated a reliable change in preference from the SD to the LD key as time elapsed from choice-trial onset.

\section{Choice-Trial Performance}

The behavior of the subjects on individual choice trials was analyzed to determine if, as Figures 1 and 2 suggest, the birds generally pecked the SD cue early in a trial and then switched to the LD cue. Based on event records from prereversal choice trials for all 9 subjects, the most frequent pattern of behavior was, in fact, an initial peck or pecks to the SD cue followed by a switch to the LD cue. This pattern was observed in $56 \%$ of all trials with at least one peck $(N=764)$. Pecking was directed exclusively to the SD cue on $29 \%$ of the trials, exclusively to the $\mathrm{LD}$ cue on $12 \%$ of the trials, and on $3 \%$ of trials, an initial peck or pecks to the LD cue was followed by a switch to the other cue. 


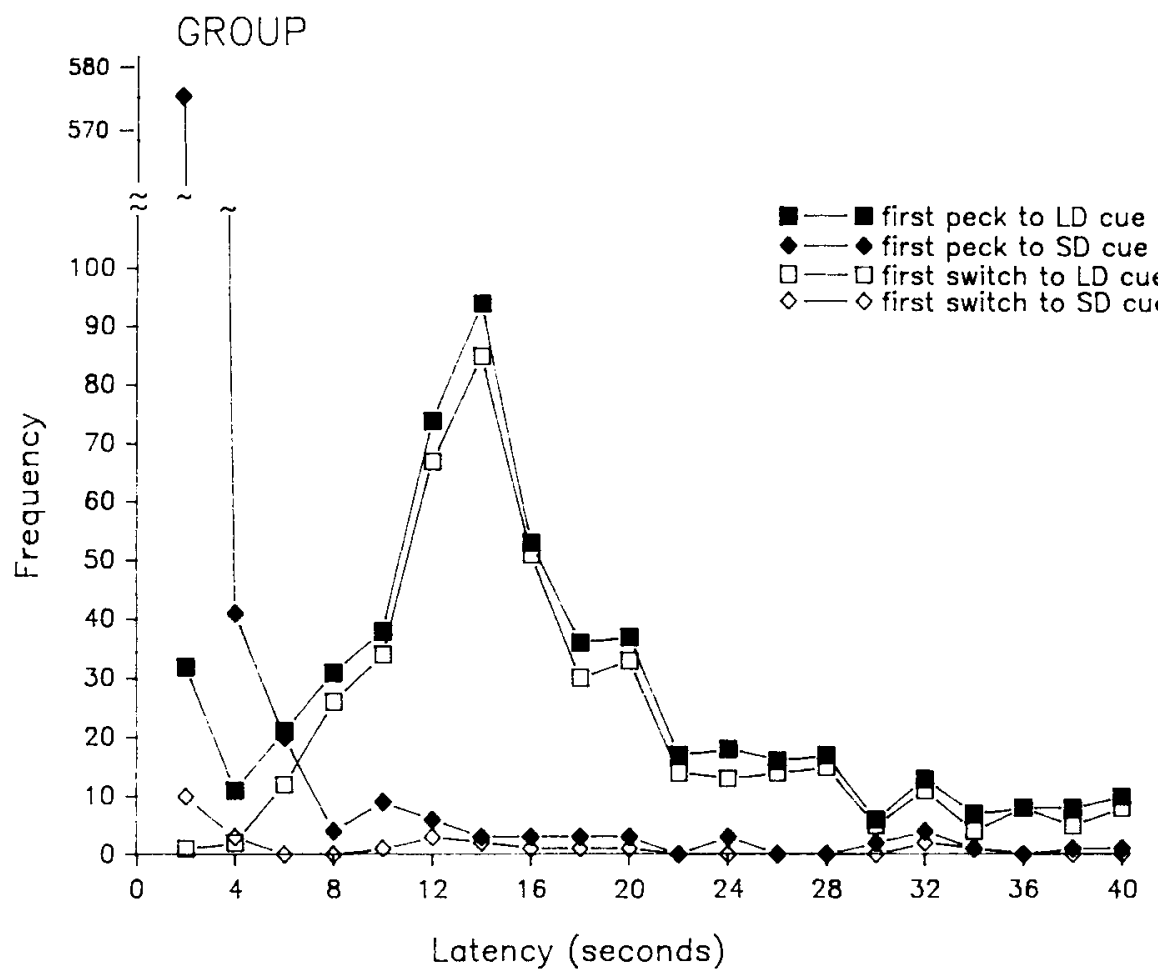

Figure 3. Frequency distributions of first-peck and first-switch latencies for each cue on choice trials. Short- and long-delay cues are indicated as SD and LD, respectively.

The frequency distribution of first-peck latency for the SD and LD cues is presented in Figure 3. In addition, the latencies of the first switch to each cue are presented as separate distributions. The first peck to the SD cue occurred within the first $2 \mathrm{sec}$ of a trial in 575 of 704 total trials with a peck to that key, with frequency falling sharply at longer latencies. Switches to the SD cue were infrequent at all latencies. In contrast, the peck-latency distribution for the LD cue peaked at values between 12 and $14 \mathrm{sec}$, as did the switch-latency distribution. It is apparent from the close correspondence of the two distributions for the LD cue that most first pecks to this cue were switches from the SD cue, except at the shortest latencies, where the distributions diverge. Within the first $2 \mathrm{sec}, 10$ of the 32 first pecks to the LD cue were followed by a switch to the SD cue, accounting for $40 \%$ of all first switches to the SD cue.

Figures 1 and 2 suggest that rates to the SD and LD cues converge toward the end of the test trials. In order to determine control by delay cues at time values well beyond those employed on training trials, choice trials of 40 min duration were run for 4 days. No systematic effect of cue upon response rate was observed during these sessions.

\section{DISCUSSION}

In the present study, the effects of delay to reinforcement on autoshaped keypecking were reliably indexed by some measures of maintained responding, but not by others. Of three measures pertaining to the first peck in a trial, two differed between delay conditions. For trials with at least one peck, the first peck was more likely to be directed to the cue associated with the shorter CS-US interval (the SD cue), and peck latency was shorter for the SD than for the LD cue. Overall probability of pecking did not differ between cues. When average rates of responding were considered, higher rates to the SD cue were observed during the pre-US period on choice, but not on probe, trials. No consistent effects of delay were observed when rates of responding were averaged across the entire 40-sec test-trial duration. The most informative index of delay effects was momentary rate of responding during choice trials. Rate of responding to the SD cue was reliably higher than rate to the LD cue early in the trial, with this difference reversing as time elapsed. A similar, but statistically unreliable, effect was observed during probe trials.

In some respects, these data join those of O'Connell and Rashotte (1982) in demonstrating greater sensitivity of momentary versus overall rate of responding to parameters of reinforcement. In their study, differential temporal patterns of responding were generated by cues associated with different amounts of reinforcement. These patterns resulted in response strength that was higher for the cue associated with the more favorable conditions of reinforcement only during the early portion of the trial. In accounting for their data, O'Connell and Rashotte invoked the notion that pigeons' behavior under autoshaping procedures is influenced by competing tendencies to 
approach the CS and the US (Boakes, 1977; Buzsaki, 1982; Gibbon et al., 1980). Under this analysis, associative strength acquired by the CS may be viewed as governing an unvarying tendency to approach that cue; however, strength of the US-approach tendency grows with elapsed trial time, yielding a net decrease in CS-directed behavior and paradoxically low overall rates of responding. The extent to which US-directed behavior competes with keypecking is directly related to parameters of the US. For example, O'Connell and Rashotte found that rate of keypecking was a negatively accelerated nonmonotonic function of elapsed trial time when US magnitude was high, but a monotonic function when US magnitude was low.

Although the analysis of temporal patterning based on US approach is consistent with differential response rates at trial onset, it does not anticipate the observation in the present study of the reversal in relative rate of responding that occurred beyond the shorter CS-US interval. Such time-dependent rate changes may be understood in terms of a stimulus-control analysis in which elapsed time is posited as a component of a compound CS that may enter into an associative relation with the US. Accordingly, the stimulus events paired with the US in the prereversal phase, for instance, would be described as compounds of green plus a 6-sec duration and red plus a 14-sec duration. As time since trial onset elapses, therefore, the timeplus-color compounds associated with the higher value would shift from the green to the red cue.

Temporal control has recently been described in terms of a model of an internal clock (e.g., Church, 1984; Gibbon \& Church, 1984). The model posits several distinct components, including an accumulator that stores current (e.g., elapsed) subjective time, a reference memory that stores previously encountered subjective times (e.g., CS-US interval) transmitted to it from the accumulator, and a comparator that assesses both accumulator and reference-memory components. The comparator activates the response mechanism when it detects a match between current and remembered times.

A stimulus-control analysis of the present data raises a question about the role of the color component of the CS. In accordance with the clock model, colors may serve as retrieval cues that access different reference memories. In addition, colors may accrue differential associative value in accordance with current theories of conditioning (Gibbon \& Balsam, 1981; Rescorla \& Wagner, 1972). There is no convincing evidence in the present data that differential value accrues to color, exclusive of control by elapsed time. Molar analyses predict stronger control of pecking by the SD than by the LD cue, an outcome not supported by overall rate measures. It could be argued that response patterns controlled by elapsed time masked differential control by color, even though no such control was evident at the end of the 40 -sec test trials, when temporal control should have been minimal. However, choice-test trials of 40-min duration also failed to reveal a preference for the SD cue.

On the other hand, the present data support the assumption that colors direct retrieval by the comparator from different (6- or 14-sec) reference memories. For choice trials, this assumption entails a single accumulator in which subjective time in the presence of one color is added to previously accumulated time in the presence of the other color, as birds switch between colors during test trials. Evidence from studies of fixed-interval (FI) schedules with rats (Roberts \& Church, 1978) and pigeons (Cabeza de Vaca, Brown, \& Hemmes, 1987) supports such a property of the accumulator (but cf. Roberts, Cheng, \& Cohen, 1989).

The temporal pattern of behavior described here has implications for the role of the CS-US interval in Pavlovian procedures. First, it extends to the autoshaping procedure evidence of control of the conditioned response by the temporal locus of US presentation, a phenomenon amply demonstrated in other Pavlovian preparations (e.g., Ellison, 1964; Kimmel, 1965; Levey \& Martin, 1968; Millenson et al., 1977). Second, it has consequences for conditioning theory. Investigations guided by prevailing theories of acquisition (e.g., Gibbon \& Balsam, 1981; Rescorla \& Wagner, 1972) have tended to rely on molar estimates of response strength, on the basis of the notion that the relative duration of the CS-US interval controls the overall amount of value or expectancy accruing to the CS. However, the assumption of a homogeneous distribution of value across the interval is difficult to reconcile with the present data on maintained responding. If rate is taken as a monotonic transform of value, the present findings indicate that the values accruing to short and long CSs are strongly dependent upon elapsed time. Thus, a long CS exhibits weaker behavioral control than does a short CS at shorter elapsed times, but the reverse is true at longer times.

Delay effects upon pre-US rate for Squad 1 were in line with the results of Cooper and Brownstein (1985). In their between-groups design, total CS duration was held constant while US delay was varied, with a maximum delay equaling total $\mathrm{CS}$ duration. Acquisition was retarded and pre-US rate declined as delay increased. According to scalar expectancy theory (SET), no effect of the delay manipulation on acquisition would be expected, since all delay conditions were associated with equivalent $\mathrm{CS} \mathrm{du}$ rations (Gibbon \& Balsam, 1981). On the basis of their data, Cooper and Brownstein suggested a modification to SET according to which an added parameter governs effective trial duration that may vary from pre-US duration to total CS duration. In the present study, the absence of a difference between Squads 1 and 2 indicates that for both groups, effective CS duration was equal to pre-US duration. Evidence for the role of total CS duration in SET derives from the split-trials procedure (Gibbon \& Balsam, 1981), in which segments of the CS are distributed across the interreinforcer interval. An important assumption is that all segments of the CS are equally detected. However, presentation of the CS immediately following the US may not constitute a functional cue, since pigeons withdraw from the CS/US site immediately following US offset (Cohen \& Campagnoni, 1989; Staddon \& Simmelhag, 1971). It is possible that such behavior is 
a determinant of the value of Cooper and Brownstein's parameter.

\section{REFERENCES}

Balsam, P. (1984). Relative time in trace conditioning. In J. Gibbon \& L. Allan (Eds.), Annals of the New York Academy of Sciences: Vol. 423, Timing and time perception (pp. 211-227). New York: New York Academy of Sciences.

BAlsaM, P. D., \& PAYNe, D. (1979). Intertrial interval and unconditioned stimulus durations in autoshaping. Animal Leaming \& Behavior, 7, 477-482.

Black, A. H., \& Prokasy, W. F. (1972). Classical conditioning: II: Current research and theory. New York: Appleton-Century-Crofts.

Boakes, R. A. (1977). Performance on learning to associate a stimulus with positive reinforcement. In H. Davis \& H. M. B. Hurwitz (Eds.), Operant-Pavlovian interactions (pp. 67-101). Hillsdale, NJ: Erlbaum.

Buzsakl, G. (1982). The "where is it?" reflex: Autoshaping the orienting response. Journal of the Experimental Analysis of Behavior, 37, $461-484$

Cabeza de Vaca, S., Brown, B. L., \& Hemmes, N. S. (1987, May). Stimulus control of discrete-trial FI. Poster presented at the annual meeting of the Association for Behavior Analysis, Nashville, TN.

Church, R. M. (1984). Properties of the internal clock. In J. Gibbon \& L. Allan (Eds.), Annals of the New York Academy of Sciences: Vol. 423. Timing and time perception (pp. 566-582). New York: New York Academy of Sciences.

Cohen, P. S. \& Campagnoni, F. R. (1989). The nature and determinants of spatial retreat in the pigeon between periodic grain presentations. Animal Learning \& Behavior, 17, 39-48.

COOPER, L. D., \& BrownSTEIN, A. J. (1985). Immediacy of reinforcement in autoshaping with pigeons. Psychological Record, 35, 353-364.

Crawford, L. L., Steirn, J. N., \& Pavik, W. B. (1985). Withinand between-subjects partial reinforcement effects with an autoshaped response using Japanese quail (Coturnix coturnix japonica). Animal Leaming \& Behavior, 13, 85-92.

ELusoN, G. D. (1964). Differential salivary conditioning to traces. Journal of Comparative \& Physiological Psychology, 57, 373-380.

Gibbon, J., Baldock, M. D., Locurto, C., Gold, L., \& Terrace, H. (1977). Trial and intertrial durations in autoshaping. Journal of Experimental Psychology: Animal Behavior Processes, 3, 264-284.

GibBon, J., \& BALSAM, P. (1981). Spreading association in time. In C. M. Locurto, H. S. Terrace, \& J. Gibbon (Eds.), Autoshaping and conditioning theory (pp. 219-253). New York: Academic Press.

GibBon, I., \& CHURCH, R. M. (1984). Sources of variance in an information processing theory of timing. In $\mathrm{H}$. L. Roitblat, T. G. Bever, \& H. S. Terrace (Eds.), Animal cognition (pp. 465-488). Hillsdale, NJ: Erlbaum.

Gibbon, J., Farrell, L., Locurto, C. M., Duncan, H. J., \& TerRACE, H. S. (1980). Partial reinforcement in autoshaping with pigeons. Animal Learning \& Behavior, 8, 45-59.

Gonzalez, F. A. (1974). Effects of varying the percentage of key illuminations paired with food in a positive automaintenance procedure. Journal of the Experimental Analysis of Behavior, 22, 483-489.

Jenkins, H. M., Barnes, R. A., \& Barerra, F. J. (1981). Why trial autoshaping depends on trial spacing. In C. M. Locurto, H. S. Terrace, \& J. Gibbon (Eds.), Autoshaping and conditioning theory (pp. 255-284). New York: Academic Press.

Kay, D. L., Hemmes, N. S., \& Brown, B. L. (1984, April). Choice measures and the assessment of temporal control in autoshaping. Paper presented at the annual meeting of the Eastern Psychological Association, Baltimore.

Kimme L, H. D. (1985). Instrumental inhibitory factors in classical conditioning. In W. F. Prokasy (Ed.), Classical conditioning (pp. 148171). New York: Appleton-Century-Crofts.

LeVEy, A. B., \& MARTIN, I. (1968). Shape of the conditioned eyelid response. Psychological Review, 75, 398-408.

Lucas, G. A., Deich, J. D., \& Wasserman, E. A. (1981). Trace autoshaping: Acquisition, maintenance, and path dependence at long trace intervals. Journal of the Experimental Analysis of Behavior, 36, 61-74.

Millenson, J. R., Kehoe, E. J., \& Gormezano, I. (1977). Classical conditioning of the rabbit's nictitating membrane response under fixed and mixed CS-US intervals. Learning \& Motivation, 8, 351-366.

NewLIN, R., \& LoLoRdo, V. M. (1976). A comparison of pecking generated by serial, delay and trace autoshaping procedures. Journal of the Experimental Analysis of Behavior, 25, 227-241.

O'Connell, J. M., \& RashotTe, M. E. (1982). Reinforcement magnitude effects in first- and second-order conditioning of directed action. Learning \& Motivation, 13, 1-25.

Pavlov, I. P. (1927). Conditioned reflexes. London: Oxford University Press.

Perkins, C. C., Beavers, W. O., Hancock, R. A., Hemmendinger, P. C., Hemmendinger, D., \& RuCCl, J. A. (1975). Some variables affecting rate of key pecking during response-independent procedures (autoshaping). Journal of the Experimental Analysis of Behavior, 24, 59-72.

Picker, M., Grossett, D., Thomas J., \& Poling, A. (1984). Negative automaintenance: Performance of pigeons under selective omission training procedures. Psychological Record, 34, 297-311.

Picker, M., \& Poling, A. (1982). Choice as a dependent measure in autoshaping: Sensitivity to frequency and duration of food presentation. Joumal of the Experimental Analysis of Behavior, 37, 393-406.

Poling, A., Thomas, J., Hall-Johnson, E., \& Picker, M. (1985). Self-control revisited: Some factors that affect autoshaped responding. Behavioural Processes, 10, 77-85.

Rescorla, R. A., \& Wagner, A. R. (1972). A theory of Pavlovian conditioning: Variations in the effectiveness of reinforcement and nonreinforcement. In A. H. Black \& W. F. Prokasy (Eds.), Classical conditioning: II: Current research and theory (pp. 64-99). New York: Appleton-Century-Crofts.

RoberTS, S., \& CHURCH, R. M. (1978). Control of an internal clock Joumal of Experimental Psychology: Animal Behavior Processes, 4, 318-337.

Roberts, W. A., Cheng, K., \& Cohen, J. S. (1989). Timing light and tone signals in pigeons. Journal of Experimental Psychology: Animal Behavior Processes, 15, 23-35.

Staddon, J. E. R., Simmelhag, V. L. (1971). The "superstition" experiment: A reexamination of its implications for the principles of adaptive behavior. Psychological Review, 78, 3-43.

(Manuscript received February 9, 1989; revision accepted for publication August 29, 1989.) 